\title{
Subcoronary Implantation or Aortic Root Replacement for Human Tissue Valves: Sufficient Data to Prefer Either Technique?
}

\author{
Tineke P. Willems, MD, Lex A. van Herwerden, MD, Ewout W. Steyerberg, MSc, \\ Meindert A. Taams, MD, Veronica E. Kleyburg, Raymond B. Hokken, MD, \\ Jos R. T. C. Roelandt, MD, and Egbert Bos, MD, PhD
}

Departments of Cardio-Pulmonary Surgery, Cardiology, and Public Health, Thoraxcenter, University Hospital Rotterdam-Dijkzigt and Erasmus University, Rotterdam, the Netherlands

The aortic root replacement technique with aortic allograft or pulmonary autograft might be superior to the subcoronary allograft implantation technique with regard to aortic regurgitation. We explored the influence of the learning process on the incidence of reoperation and the severity of postoperative aortic regurgitation as assessed by color Doppler echocardiography. The subcoronary implantation technique was used in 81 patients, and root replacement was done in 63 patients. The first 30 patients of each group were considered as the surgeons' learning curve. Reoperations were more common in the subcoronary implantation group. After exclusion of early reoperations, the median regurgitation score based on

$\mathrm{H}$ uman tissue valves are increasingly used for aortic valve replacement, and good long-term results have been reported [1, 2]. It is still under debate, however, which surgical technique to use: the subcoronary implantation or aortic root replacement.

The disadvantage of root replacement is the radical surgical approach for aortic valve replacement. An argument in favor of implantation of the human tissue valve as a functional unit is the lower incidence of early reoperation compared with the subcoronary implantation technique [3-5]. Furthermore, recent reports have suggested that aortic regurgitation on color Doppler echocardiography is less prominent after aortic root replacement than after subcoronary implantation $[3,4]$.

Several factors may influence the results of either technique, and the learning curve for the surgical procedure is an important one. Other factors, such as the grouping of echocardiographic data, also may have influenced the interpretation of previous follow-up studies $[6,7]$. The purpose of this interim report is to explore the influence of the learning process on the incidence of reoperation and the severity of postoperative aortic regurgitation as assessed by color Doppler echocardiography.

Presented at the VI International Symposium for Cardiac Bioprostheses, Vancouver, BC, Canada, July 29-31, 1994.

Address reprint requests to Dr Willems, Department of CardioPulmonary Surgery, Bd 156, Dr Molewaterplein 40, 3015 GD Rotterdam, the Netherlands. echocardiographic examination was 0.22 in the first 30 patients from the subcoronary implantation group and 0.14 in the root replacement group. The subsequent patients from these groups had regurgitation scores of 0.20 and 0.17 , respectively. Statistical analysis of these data showed no significant difference. This interim report suggests that the learning curve for the surgical procedure and the grouping of echocardiographic data influence the interpretation of follow-up studies. The superiority of either technique with regard to aortic regurgitation has yet to be proved.

(Ann Thorac Surg 1995;60:S83-6)

\section{Material and Methods}

Patient Population

From May 1987 to June 1994, 144 adult patients underwent implantation of a human tissue valve in the aortic position. In 81 patients the subcoronary implantation technique was used, and in 63 patients the aortic root replacement technique was done. An aortic allograft was used in all subcoronary implantations and in 37 of the root replacements. The pulmonary autograft was used for aortic root replacement in 26 patients. The mean age and sex distributions of the patients undergoing the different procedures were as follows: subcoronary implantation, 47 years (range, 17 to 83 years) and $31 \%$ female; allograft root replacement, 44 years (range, 17 to 74 years) and $41 \%$ female; autograft root replacement, 26 years (range, 17 to 42 years) and $50 \%$ female.

The hospital mortality rates for subcoronary implantation and aortic root replacement were $4.9 \%$ (4 patients) and $4.8 \%$ ( 3 patients), respectively. The median duration of follow-up for the hospital survivors was 28 months (range, 2 to 81 months) in the subcoronary implantation group and 22 months (range, 2 to 62 months) in the aortic root replacement group.

\section{Surgical Techniques}

Surgical procedures were performed using standard cardiopulmonary bypass with moderate hypothermia, myo- 
cardial protection with crystalloid cardioplegia (St. Thomas solution), and topical cooling.

The subcoronary implantation technique was initially applied with scalloping of each sinus of Valsalva in 32 patients. Subsequently, the valves have been implanted in 49 patients with preservation of the aurtic wall of the noncoronary sinus, a technique introduced by Ross [8]. Aortic root replacement with the aortic allograft or pulmonary autograft was performed with reimplantation of the coronary ostia [9]. In cases in which the autologous pulmonary valve was used, it was replaced by a pulmonary allograft $[10]$.

There were important differences in the indications for a particular procedure. The allograft root replacement technique was mainly used in patients with a major aortic root pathologic process or valve disease associated with ancurysm of the ascending aorta. The autograft root replacement and the subcoronary implantation technique were mainly performed in patients with isolated aortic valve disease. The autograft root replacement technique was chiefly applied in young adult patients.

\section{Echocardiographic Methods}

Since March 1993 the structure, function, and competence of the implanted allograft valves in these patients have been assessed by echocardiography at 6- to 12 month intervals. The protocol for precordial echocardiographic examinations of allograft and autograft recipients includes the following. All examinations are performed on a Vingmed CFM 750 ultrasound system (Vingmed, Trondheim, Norway) with a $3.25-\mathrm{MHz}$ transducer. Two technicians were trained and instructed to perform the echocardiography. The gain is standardized during color Doppler echocardiographic examination of the left ventricular outflow tract for regurgitant flow signals by starting at low gain and adjusting the gain upward just until white noise appears. The flow velocity reject is set at $0.25 \mathrm{~m} / \mathrm{s}$. The instrument settings at the first examination of the patient are noted and used during follow-up examinations. Aortic regurgitation is considered to be present by color Doppler echocardiographic examination when diastolic flow signals originating from the aortic valve are visualized in the left ventricular outflow tract. This flow is described qualitatively as laminar flow with an abnormal direction (away from the aortic valve during diastolc) or as turbulent flow seen as a mosaic pattern.

The severity of aortic regurgitation is determined according to Perry and associates [11]. The ratio of the regurgitant jet diameter to the systolic left ventricular outflow tract diameter is measured in the parasternal long-axis view. This ratio will be referred to as the jet-diameter ratio. During the examination, the imaging plane is angled to demonstrate the maximal diameter of the regurgitant jet. The jet diameter is measured just below the aortic valve. Diamelers are measured on-line on the video screen by planimetry using a trackball to trace the frozen images. The mean values of measurements in two cardiac cycles are noted. The results are reviewed by one cardiologist. These measurements correlate well with angiographic estimates of the severity of aortic regurgitation. A numeric grade was assigned ac- cording to the available threshold values, as determined by Perry and colleagues [11]: grade 0 , jet-diameter ratio 0 ; grade 1 , ratio 0.01 to 0.24 ; grade 2 , ratio 0.25 to 0.46 ; grade 3 , ratio 0.47 to 0.64 ; grade 4 , ratio 0.65 or greater.

\section{Echocardiographic Follow-Up}

Postoperative echocardiograms were available in 50 patients who underwent subcoronary implantation, with a median interval after operation of 32 months (range, 12 to 78 months). In 39 patients with aortic root replacement, an echocardiogram was available with a median postoperative interval of 23 months (range, 6 to 62 months). Unavailable for echocardiographic analysis were 7 patients who died in the hospital. Also excluded were the 37 patients who were within the 6-month postoperative follow-up and 9 patients who had reoperations. Two patients were lost for echocardiographic follow-up.

\section{Data Analysis}

Kaplan-Meier curves were constructed to estimate the 2-year cumulative incidence of reoperation. Differences between curves were evaluated with the log-rank test.

Box plots were used to depict the distribution of the jet-diameter ratios [12]. The box shows the median and the $25 \%$ to $75 \%$ interquartile range, and contains $50 \%$ of the measured jet-diameter ratios. Moreover, the box plots show the values within 1.5 times the interquartile range and outlying values.

The numeric grade for severity of aortic regurgitation and the median regurgitation scores were compared with a nonparametric test (Mann-Whitney) [13].

\section{Results}

Assessment of the severity of postoperative aortic regurgitation allows us to describe which surgical techniquethe subcoronary implantation or aortic root replacement-is the technique of choice. This was analyzed by the incidence of reoperation and by the severity of aortic regurgitation during echocardiographic follow-up.

Successful implantation of human tissue valves is highly related to the surgeon's experience with the techniques of subcoronary implantation and root replacement. Therefore, we considered the results from the first 30 operated patients of each group as the learning curve. The incidences of reoperation in the first 30 operated patients and in the subsequent operated patients were compared for both techniques.

The echocardiographic analysis was used to detect functional postoperative differences between the implantation techniques. Therefore, reoperations were excluded in this echocardiographic analysis. To assess whether the echocardiographic data were still influenced by the learning curve, we compared the data of the first 30 patients with the data of the subsequent operated patients.

\section{Reoperation}

The total 2-year cumulative incidence of reoperation was $11 \%$ (six of 81 ) in the subcoronary implantation group and $7 \%$ (three of 63 ) in the aortic root replacement group. One patient was excluded from further analysis because 
the indication for reoperation was not considered to contribute to the description of the learning curve. This patient received a pulmonary autograft and had reoperation for severe aortic regurgitation due to recurrent acute rheumatic fever [14]. Reoperation for severe aortic regurgitation could be considered as an expression of the learning curve in 8 of 144 patients (2-year rate $8 \%$ ). In 2 patients who had reoperation in the subcoronary implantation group, the learning errors were identified as errors in judgment, and root replacement would have been indicated. Four patients with subcoronary implantation and 2 patients with an allograft root replacement had reoperations because of technical errors.

Five reoperations occurred among the first 30 patients from the subcoronary implantation group (2-year rate $17 \%$ ). There was one reoperation in the subsequent 51 patients from the subcoronary implantation group (2\%). In the first 30 patients from the root replacement group, there were two reoperations (2-year rate $7 \%$ ). The subsequent 33 patients with root replacement were free of reoperation. These differences in the cumulative incidence of reoperation were not statistically significant $(p>0.20)$.

\section{Doppler Echocardiographic Analysis}

The jet-diameter ratio was used to estimate the severity of aortic regurgitation. The numcric grades for the severity of aortic regurgitation are shown in Figure 1. Eight and 5 patients among the first 30 from the subcoronary implantation and root replacement groups, respectively, had a regurgitation grade of 2 or more. The subsequent patients from both groups had a significant difference in the severity of aortic regurgitation: 11 subcoronary implantation patients had grade 2 or more aortic regurgitation, in contrast to only 1 patient who had a root replacement $(p=0.02)$.

When median jet-diameter ratios were compared, different results were found (Fig 2). The median jetdiameter ratio was 0.22 (range, 0 to 0.46 ) in the first 30 patients with a subcoronary implantation and 0.14 (range, 0 to 0.54 ) in the first 30 patients with a root

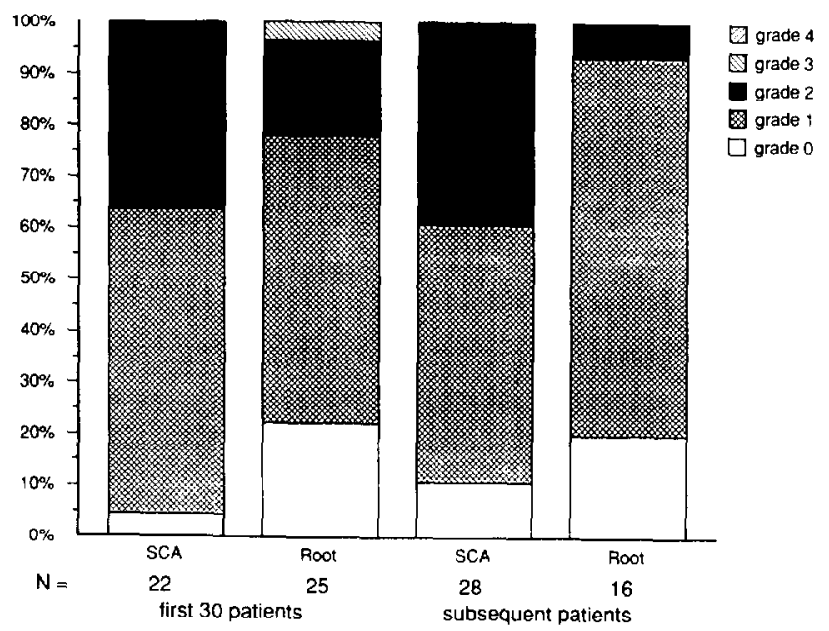

Fig 1. Cumulative distribution of severity of aortic regurgitation after grading of jet-diameter ratios in the first 30 patients and subspquent patients for both implantation techniques. $(\mathrm{SCA}=$ subcoronary implantation.)

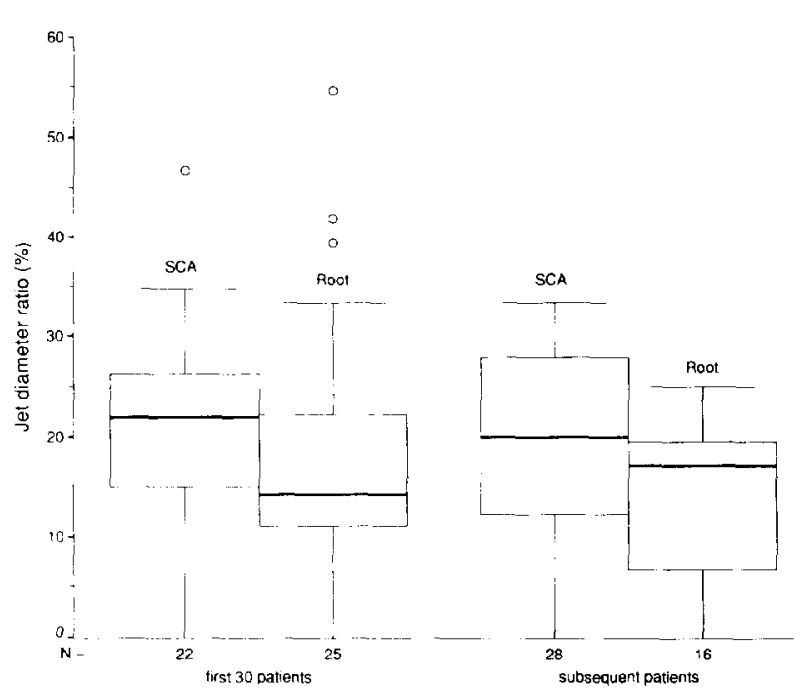

Fig 2. Median jet-diameter ratios for the first 30 patients and subsequent patients for the subcoronary implantation (SCA) and root replacement techniques. Median value is denoted (heavy line). The interquartile range is included within the box, which contains $50 \%$ of the measured jet-diameter ratios. The values within 1.5 times the interquartile range are included (error bar). The outlying values are denoted (circles).

replacement. The subsequent patients from the subcoronary implantation and root replacement groups had median jet-diameter ratios of 0.20 (range, 0 to 0.30 ) and 0.17 (range, 0 to 0.25 ), respectively. These differences in median jet-diameter ratios were not statistically significant $(\mu>0.05)$. If the total experience for both techniques was analyzed, the median jet-diameter ratios were 0.21 (range, 0 to 0.46 ) in the subcoronary implantation group and 0.15 (range, 0 to 0.54 ) in the root replacement group. This difference was statistically significant $(\mu=0.02)$.

\section{Comment}

Replacement of the aortic valve as a total root might be superior to allograft implantation with the subcoronary allograft implantation technique with regard to aortic valve regurgitation.

There are technical advantages in the aortic root replacement technique. The matching of allograft size with the host annulus is less critical, and implantation of the graft as a functional unit is less prone to surgical error [4]. In general, root replacement is a firmly established surgical technique as shown by the use of other types of valved conduits. A disadvantage of root replacement is its radical approach as a technique for aortic valve replacement. During late follow-up, calcification of the original allograft aortic wall is common. This may have consequences for the development of aortic valve regurgitation and may eventually influence the complexity of reoperations [15]. Aortic root replacement may be the preferable technique, but firm data to support this contention are not available. Because long-term clinical results concerning these problems are yet to come, the choice is currently based on the incidence of early reoperation and the development of aortic regurgitation on color Doppler echocardiography. 


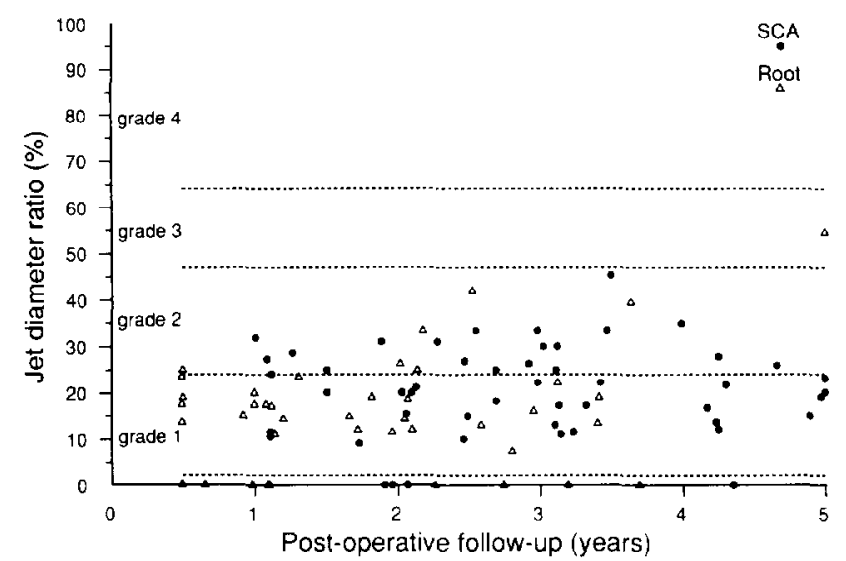

Fig 3. Distribution of jet-diameter ratios during postoperative follow-up. (Dashed lines = thresholds determined by Perry and colleagues [11]; SCA = subcoronary implantation.)

Reoperations were more common in the first 30 patients after subcoronary implantation than after root replacement. This finding after subcoronary implantation is comparable to the early experience of Jones [3], who reported five reoperations in the first 31 patients. The incidence of early reoperation suggests that surgical experience is an important factor and a learning curve is apparent. In clinics with a resident training program, this is an additional argument for performing the root replacement technique. For surgeons with experience in the subcoronary implantation technique, the choice is more complex and largely supported by echocardiographic follow-up data.

Recent echocardiographic studies have shown a lower incidence of aortic regurgitation after root replacement than after subcoronary implantation of human tissue valves [3,6]. In these studies, the consequences of the surgeons' learning curve were included in the echocardiographic analysis. Thus, the results may be biased by a learning effect, which is more prominent for the subcoronary implantation technique $[3,6]$. We excluded from our echocardiographic data early reoperations for aortic regurgitation due to plain technical failure. After this adjustment, we observed no major differences between the root replacement and the subcoronary implantation technique.

If our same data are grouped by grading of the severity of regurgitation according to Perry and associates [11], less aortic regurgitation was observed with the root replacement technique than with the subcoronary implantation technique. This contradiction is explained by the following considerations. Grading of aortic regurgitation with color Doppler echocardiography for the purpose of this analysis lacks sufficient validation. The thresholds as defined by Perry and colleagues [11] were based on a limited number of observations in patients with grades 1 and 2 regurgitation. Basically, these measurements differentiate bctween grade 1 or 2 (minor) and grade 3 or 4 (major) aortic valve regurgitation. Figure 3 shows that the jet-diameter ratios are clustered around the threshold value between grades 1 and 2 . A small shift of this threshold value has major consequences for the interpretation of echocardiographic data and study re- sults. In addition, from a statistical point of view, the original jet-diameter ratios are preferred over grouping of data. Grading is useful in clinical practice but is less valid for calculated comparisons of implantation techniques.

On the basis of our echocardiographic analysis, it appears that aortic root replacement is not superior to the subcoronary implantation technique. The higher incidence of reoperation during the learning curve for the subcoronary implantation technique is an important limitation. Longer clinical follow-up with a predetermined echocardiographic protocol could provide more definite information on both implantation techniques with regard to long-term aortic valve function.

This research was supported by grant 42.001 from the Netherlands Heart Foundation. Doctor Willems was the recipient of the Scientific Committee Award.

We gratefully acknowledge the secretarial assistance of Ada Matzer.

\section{References}

1. Barratt-Boyes BG, Roch AHG, Subramanyan R, Pemberton JR, Whitlock RML. Long-term follow-up of patients with the antibiotic-sterilized aortic homograft valve inserted freehand in the aortic position. Circulation 1987;75:768-77.

2. O'Brien MF, McGiffin DC, Stafford EG, et al. Allograft aortic valve replacement: long-term comparative clinical analysis of the viable cryopreserved and antibiotic $4^{\circ} \mathrm{C}$ stored valves. J Cardiac Surg 1991;6(Suppl 4):534-43.

3. Jones EL. Freehand homograft aortic valve replacementthe learning curve: a technical analysis of the first 31 patients. Ann Thorac Surg 1989;48:26-32.

4. Knott-Craig CJ, Elkins RC, Stelz PL, et al. Homograft replacement of the aortic valve and root as a functional unit. Ann Thorac Surg 1994;57:1501-6.

5. Kouchoukos NT, Davilla-Roman VG, Spray TL, Murphy SF, Perrillo JB. Replacement of the aortic root with a pulmonary autograft in children and young adults with aortic-valve disease. N Engl J Med 1994;330:1-6.

6. Daicoff GR, Botero LM, Quintessenza JA. Allograft replacement of the aortic valve versus the miniroot and valve. Ann Thorac Surg 1993;55:855-9.

7. Kirklin JK, Smith J, Novick W, et al. Long-term function of cryopreserved aortic homografts. A ten-year study. J Thorac Cardiovasc Surg 1993;106:154-66.

8. Ross D. Technique of aortic valve replacement with a homograft: orthotopic replacement. Ann Thorac Surg 1991;52: $154-6$.

9. O'Brien MF, McGiffin DC, Stafford EG. Allograft aortic valve implantation: techniques for all types of aortic valve and root pathology. Ann Thorac Surg 1989;48:600-9.

10. Schoof PH, Cromme-Dijkhuis AH, Bogers AJJC, et al. Aortic root replacement with pulmonary autograft in children. J Thorac Cardiovasc Surg 1994;107:367-73.

11. Perry GJ, Helmcke F, Nanda NC, Byard C, Soto B. Evaluation of aortic insufficiency by Doppler color flow mapping. J Am Coll Cardiol 1987;9:952-9.

12. Williamson DF, Parker RA, Kendrick JS. The box plot. A simple visual method to interpret data. Ann Intern Med 1989;110:916-21.

13. Altman DG. Practical statistics for medical research. London: Chapman and Hall, 1991:194-7.

14. Vries de $\mathrm{H}$, Bogers AJJC, Schoof $\mathrm{PH}$, et al. Pulmonary autograft failure caused by a relapse of rheumatic fever. Ann Thorac Surg 1994;57:750-1.

15. Belcher P, Ross D. Aortic root replacement: 20 years experience of the use of homografts. Thorac Cardiovasc Surg 1991;39:117-22. 